\title{
Transportal versus all-inside techniques of anterior cruciate ligament reconstruction: a systematic review
}

\author{
Rohan Bhimani ${ }^{1}$, Reza Shahriarirad ${ }^{2,3}$, Keivan Ranjbar $^{2,3}$, Amirhossein Erfani $^{2,3^{*}}$ (10 and Soheil Ashkani-Esfahani ${ }^{1}$
}

\begin{abstract}
Background: Transportal (TP) and all-inside techniques (AIT) are the most commonly used anterior cruciate ligament $(\mathrm{ACL})$ reconstruction procedures in current clinical practice. However, there is an ongoing debate over which procedure is superior. Therefore, the purpose of this systematic review was to evaluate and compare the clinical outcomes and complications of these two techniques to propose recommendations for future application. Our primary hypothesis was that AIT is a superior ACLR technique compared to TP.

Methods: A systematic literature review, using PRISMA guidelines, was conducted using PubMed, Medline, Google Scholar, and EMBASE, up to February 2021 to identify studies focusing on AIT and TP techniques of ACL reconstruction. We excluded animal experiments, cadaveric studies, retrospective studies, case reports, technical notes, and studies without quantitative data. Patients' characteristics, surgical technical features, along with postoperative followup and complications were extracted and reported accordingly. Methodological quality of the included studies was assessed using the Modified Coleman Methodology Score (MCMS).
\end{abstract}

Results: A total of 44 studies were selected for this review, of which four were comparative studies. A total of 923 patients underwent AIT and 1678 patients underwent the TP technique for ACLR. A single semitendinosus graft was commonly used in the AIT compard to combined semitendinosus and gracilis graft in the TP group. The postoperative increase in International Knee Documentation Committee (IKDC), Lysholm, KT-1000, and Short Form-12 (physical and mental) scores were similar in the AIT group and the TP group. Contrastingly, the VAS pain score was significantly lower in the AIT group compared to the TP group. Furthermore, the pooled complication rates from all studies were similar between the two groups (AIT: 54 patients, 8.26\% vs. PT: 55 patients, 6.62\%). However, the four studies that prospectively compared AIT and TP techniques showed lesser complications in the AIT group than the TP group.

Conclusion: Since the future trend in orthopedic surgery is toward less invasive and patients' satisfaction with good outcomes, AIT is a good alternative method considering preserving bony tissue and gracilis tendon with less postoperative pain, along with more knee flexor strength and equal outcomes compared to conventional ACL reconstruction surgery.

Level of Evidence II.

Keywords: Anterior cruciate ligament, Anteromedial portal, All-inside technique, Single-bundle ACL reconstruction, Femoral tunnel, Tibial tunnel

*Correspondence: Ahnerfani@gmail.com

${ }^{2}$ Thoracic and Vascular Surgery Research Center, Shiraz University of Medical Science, Shiraz, Iran

Full list of author information is available at the end of the article original author(s) and the source, provide a link to the Creative Commons licence, and indicate if changes were made. The images or other third party material in this article are included in the article's Creative Commons licence, unless indicated otherwise in a credit line to the material. If material is not included in the article's Creative Commons licence and your intended use is not permitted by statutory regulation or exceeds the permitted use, you will need to obtain permission directly from the copyright holder. To view a copy of this licence, visit http://creativecommons.org/licenses/by/4.0/. The Creative Commons Public Domain Dedication waiver (http://creativeco mmons.org/publicdomain/zero/1.0/) applies to the data made available in this article, unless otherwise stated in a credit line to the data. 


\section{Background}

Anterior cruciate ligament (ACL) injury is common in athletes, with a female predominance $[1,2]$. ACL deficit knee can result in high morbidity and long-term disability if inadequately treated [3]. The standard treatment for ACL injury is anterior cruciate ligament reconstruction (ACLR), which has evolved over time with the goal of achieving a more anatomical and less invasive reconstruction method because previous non-anatomic repairs were shown to have a higher risk of graft impingement, rotational instability, and graft attenuation [4-8]. The transportal (TP) and all-inside techniques (AIT) are the most commonly used reconstruction procedures in current clinical practice.

TP technique is a popular and widely practiced technique of ACLR, as it allows independent femoral tunnel drilling $[9,10]$. Among the advantages of this technique is it does not require special equipment, performance ease, and its ability to reach the center of the native ACL footprint [11]. However, a caveat to this technique is that it may result in disproportionate stress on the graft which increases the possibility of graft failure, rupture of the femoral posterior wall, and short femoral tunnel length $[10,12-17]$. Robin et al. in a review reported other shortcomings of TP technique such as difficulty visualizing in hyperflexion possibly leading to iatrogenic chondral injury, technically demanding, short or bicortical sockets-which may limit fixation options, higher revision rate, increased risk of injury to the common peroneal nerve, and extension loss during stance phase [18]. Furthermore, hyperflexion requires an assistant, thus entails for improving and developing better techniques [18].

AIT has been acclaimed to be an alternative to the TP technique [19]. It uses sockets in a half-way tunnel rather than full tunnels, resulting in a reduction in the postoperative pain, swelling, and likelihood of synovial fluid flow or infiltration among the space between the graft and the bone interface $[20,21]$. Furthermore, the sockets can also prevent tunnel enlargement and accelerate graft maturation due to the eradication of dead space [22]. Among the other advantages are the made small incision from a cosmetic aspect [22], less invasiveness and variety of graft choices [23]. However, AIT is associated with learning curve and increased risk of injuring extra-articular surface. Based on the aforementioned benefits and drawbacks, AIT is now considered a new option for ACL reconstruction.

While prior studies have demonstrated the utility of AIT and TP technique, fewer have elucidated superiority of one technique over the other in terms of clinical outcome [24]. Our primary hypothesis was that AIT is a superior ACLR technique compared to TP, therefore, in this review, we aimed to evaluate the available data in the literature in terms of outcome and complications of these two techniques to propose recommendations for future application. AIT is a superior ACLR technique compared to TP.

\section{Materials and methods \\ Search strategy}

Four major online databases (EMBASE, PUBMED, MEDLINE, and Google Scholar) were screened for the related literature addressing ACLR methods. Articles that were published until February 6, 2021, were enrolled. The keywords used in this study were based on MeSH terms and included "anterior cruciate ligament reconstruction," and similar phrases (Additional file 1: Table S1). Our search method was focused on the AIT and TP techniques of ACLR. In our study, the AIT was defined as creating the bone socket from the articular side of the tibia rather than the traditional full-length tunneling through the knee joint and outer cortex. [20,21]. Due to the anticipated scarcity of published literature, the search was not limited to randomized controlled trials.

\section{Study selection}

We included clinical studies involving individuals $\geq 18$ years old, articles written in English, and surgeries limited to primary ACLR or where ACLR was the primary purpose of the surgery. We excluded animal experiments, cadaveric studies, retrospective studies, case reports, technical notes, and studies without quantitative data. Furthermore, in studies with mixed populations or various techniques, only data regarding our inclusion criteria (AIT or TP) were extracted for the data analysis. Since there were no readily available criteria for anatomic ACLR, we have chosen to include all articles in which the authors stated that the reconstructive surgical procedure they performed was the AIT or TP techniques, or that the described technique used in their study indicated the use of AIT or TP.

\section{Data extraction, quality assessment and analysis}

Three reviewers screened all the selected literature independently. First of all, the abstracts were reviewed, and if the content of the abstract revealed the relevance of the results of the paper to our aims full texts would be taken into consideration. Disagreements on including or excluding the papers or interpreting the outcomes of the studies were discussed among the reviewers and resolved. The reviewers independently assessed the quality of included studies using the Coleman Methodology Score (CMS) [25]. The score is based on ten subsections derived from the CONSORT statement for randomized controlled trials. The total score is between 0 and 100. A score of 100 indicates that the study largely 


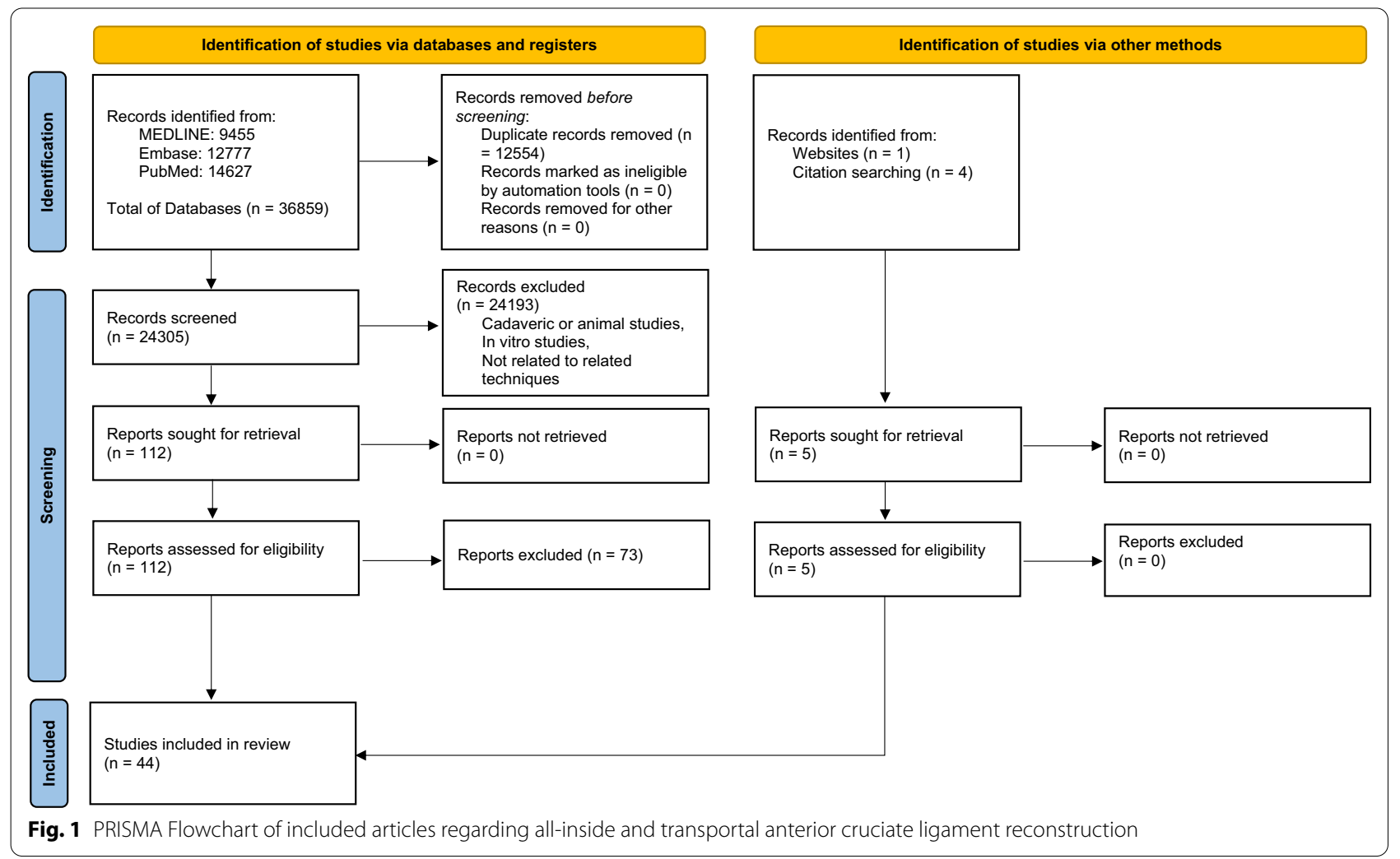

avoids chance, various biases, and confounding factors. A worksheet for data extraction was created and used to obtain a descriptive review of the reported variety of surgical and demographic data from each study (Additional file 2: Table S2). Recorded data included study characteristics (author, year of publication, sample size, and study design), descriptive statistics, and clinical data. Descriptive statistics such as means, mean differences, standard deviation (SD), and measures of variance are presented where applicable. Means of ranges are presented where distributions of data were unavailable. A pooling method of means and variances was utilized to calculate the overall outcome scores.

\section{Results}

\section{Study characteristics}

The initial search yielded a total of 36,859 articles. After excluding 12,554 duplicates, a systematic screening process ultimately yielded 44 articles, 15 full-text articles regarding AIT [26-40], 25 regarding TP technique [41-65], and four [66-69] articles regarding AIT versus TP technique which were included in this review (Fig. 1). The demographic data of the patients who underwent AIT are shown in Table 1, while patients who underwent
TP are demonstrated in Table 2. Also, the comparison of the two techniques is presented in Table 3.

\section{All-inside technique}

Among 19 articles regarding AIT [26-40, 66-69] a total of 923 cases of ACLR treated with AIT, of which their regarding data are exhibited in Tabled 1 and 3. The type of graft was mentioned in 815 patients; in 664 (81.47\%) patients semitendinosus tendon was used. In 598 patients (76.67\%) autograft was used. The average length and the diameter of grafts used were $63.58 \pm 3.69$ and $8.27 \pm 0.65$, respectively. Among the fixation techniques, suspensory fixation was a preferred choice as reported in 821 patients (Table 1).

\section{Transportal technique}

Based on the report of 29 articles [41-69], a total of 1678 patients were treated with the TP technique, of which the regarding data are exhibited in Tables 2 and 3. The type of graft used was mentioned in 1541 cases, 768 (49.83\%) used a combination of semitendinosus and gracilis tendons. Autograft was used in 1063 patients (84.3\%) while allograft was used in 198 patients (15.7\%). 
The interference screw was the preferred fixation method used in 806 patients (52.64\%) for the tibial side and 311 patients (20.31\%) for the femoral side (Table 2).

\section{All-inside versus transportal}

Among the studies included in our review, four prospective randomized studies [66-69] have compared the outcomes of the AIT to TP technique (Table 4), which included 176 AIT and 171 TP patients. The male to female ratio in these studies were 82:61 and 79:62 for AIT and TP, respectively. The average age in the groups were $27.73 \pm 10.32$ years and $29.18 \pm 9.65$ years for AIT and TP, respectively and the average BMI in the AIT groups was $25.8 \pm 5.05 \mathrm{~kg} / \mathrm{m}^{2}$ and in the TP group was $24.29 \pm 2.74 \mathrm{~kg} / \mathrm{m}^{2}$.

In terms of graft characteristics, a combination of semitendinosus and gracilis tendon (49.8\%) was the preferred graft in TP patients and isolated semitendinosus in AIT patients (81.5\%). The mean graft diameter in AIT was $8.2 \pm 0.7 \mathrm{~mm}$ for the femoral side and $8.3 \pm 5 \mathrm{~mm}$ for the tibial side while for TP the mentioned values were $7.7 \pm 0.5 \mathrm{~mm}$ and $7.7 \pm 4.9 \mathrm{~mm}$ for femoral and tibial side, respectively [67]. Among four studies, two of them used allograft $[67,68]$ for both techniques while the remaining two used autografts $[66,69]$. In other words, $68.42 \%$ of $\mathrm{TP}$ and $66.48 \%$ of AIT grafts were allografts. In addition, one study used a quadruple bundle for ACLR [67] while another study used a double bundle for ACLR [68].

\section{Physical examination and functional outcome scores}

The postoperative outcome scoring system varied among the studies and is summarized in Table 5. Among 153 AIT-ACLR patients, 145 (94.77\%) had a normal pivot shift test, while eight $(5.22 \%)$ had positive tests. Similarly, among 686 TP ACLR patients, 595 (86.73\%) had normal pivot shift test while 93 (13.27\%) had abnormal test results. Furthermore, based on the Knee Society Scoring system [40] in AIT-ACLR patients, an increase of $24.29 \pm 20.27$ for pain and $31.31 \pm 27.17$ for function during a two year follow-up was observed, while these measures were $20.84 \pm 18.75$ and $29.16 \pm 26.32$ for pain and function, respectively, during a one-year follow-up. Furthermore, when compared to the preoperative score at two years follow-up, the postoperative Lysholm score increased by 37.13 and 27.99 points in the AIT and TP groups, respectively. Moreover, no significant difference was seen in IKDC, KSS and KOOS scores between the two groups (Tables 4,5 ).

\section{Complications}

The pooled data from all the studies showed that the similar complication rates in AIT and TP techniques
(8.26 percent vs. 6.62 percent, respectively) - with graft failure, ACL failure, and paresthesia being the most common complications (Table 3). The four studies that directly compare AIT and TP techniques [66-69], on the other hand, showed that three patients in the AIT group had post-operative complications such as ACL failure $(n=1)$, septic arthritis $(n=1)$, and cyclops syndrome $(n=1)$. In the TP group, however, five patients developed complications: ACL failure $(n=2)$, hemarthrosis $(n=1)$, and cyclops syndrome $(n=2)$.

\section{Discussion}

The literature review did not identify a significant difference in post-operative functional outcomes between AIT and TP group. However, post-operative VAS pain scores and complications rates was lower AIT group compared to the TP group in studies directly comparing the two techniques prospectively, suggesting AIT as a good alternative method, especially when treating athletes with ACL injury.

With the increase of ACL reconstruction surgeries worldwide, assessing various techniques is essential to improve patient's long-term functional outcomes by selecting the most suitable method. In this systematic review, we aimed to compare TP-ACLR as a conventional technique with AIT-ACLR as a developing technique through different aspects such as technique-related features and their clinical outcomes. Based on the reviewed literature, AIT and TP technique each has its own advantages and disadvantages; however, AIT is a suitable alternative method considering preserving bony tissue and gracilis tendon with less post-operative pain and complications, along with more knee flexor strength and equal outcomes compared to TP technique. Ultimately, the method of choice is based upon the surgeon's available equipment; graft choice; experience; efficiency; patient age and activity level; and cosmesis and other relative factors.

An important aspect of ACL reconstruction is the creation of the femoral tunnel. Throughout time, the technique of choice for ACLR has shifted from the transtibial technique to the TP technique, which independently utilizes an anteromedial (AM) arthroscopic portal or an accessory AM portal for anatomic femoral tunnel reconstruction [24, 70]. The accessory AM portal offers numerous advantages including (I) By operating through the AM accessory portal as a viewing portal, we bypass the lateral femoral as a visual obstacle and therefore achieve better femoral tunneling. Also, following the tunnel position is attainable without taking out the drilling device Altering the obliquity of the accessory portal provides establishing femoral tunnel 


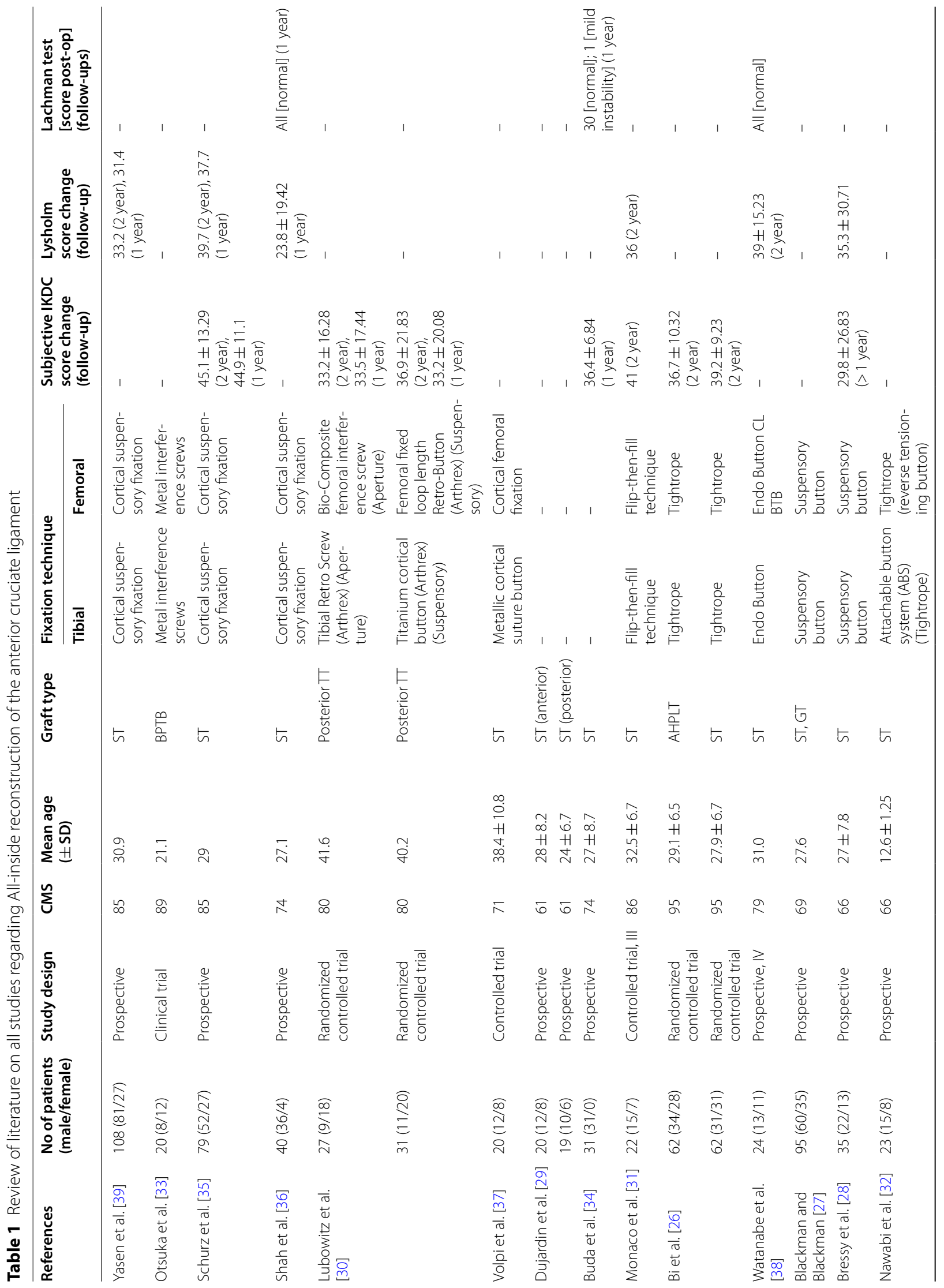




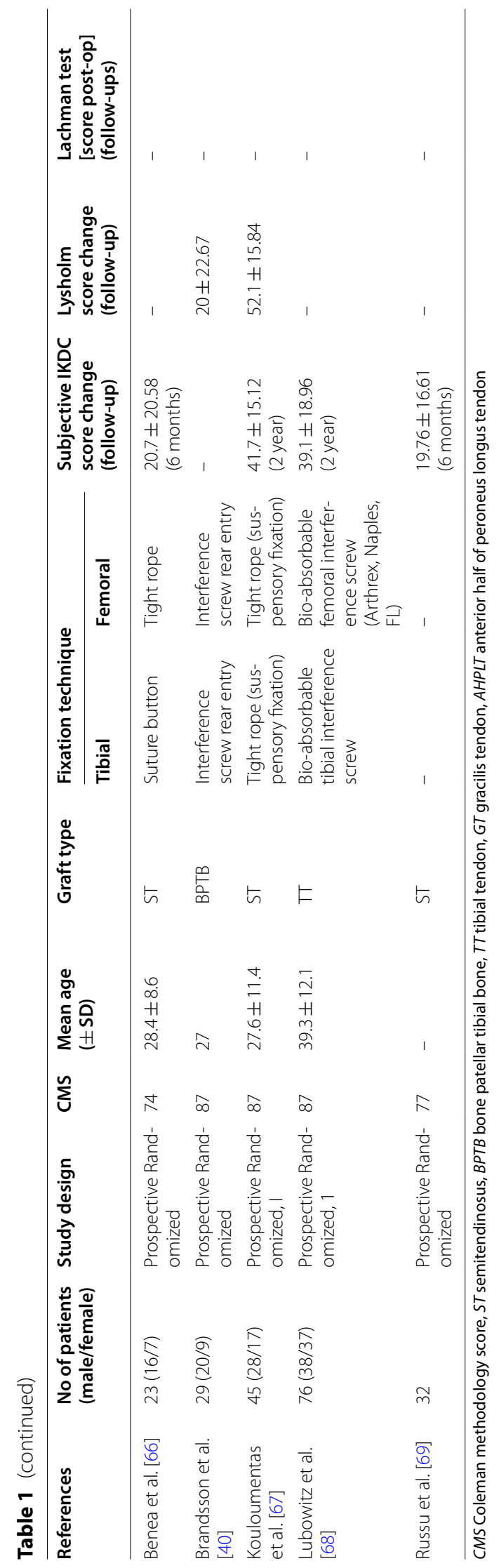




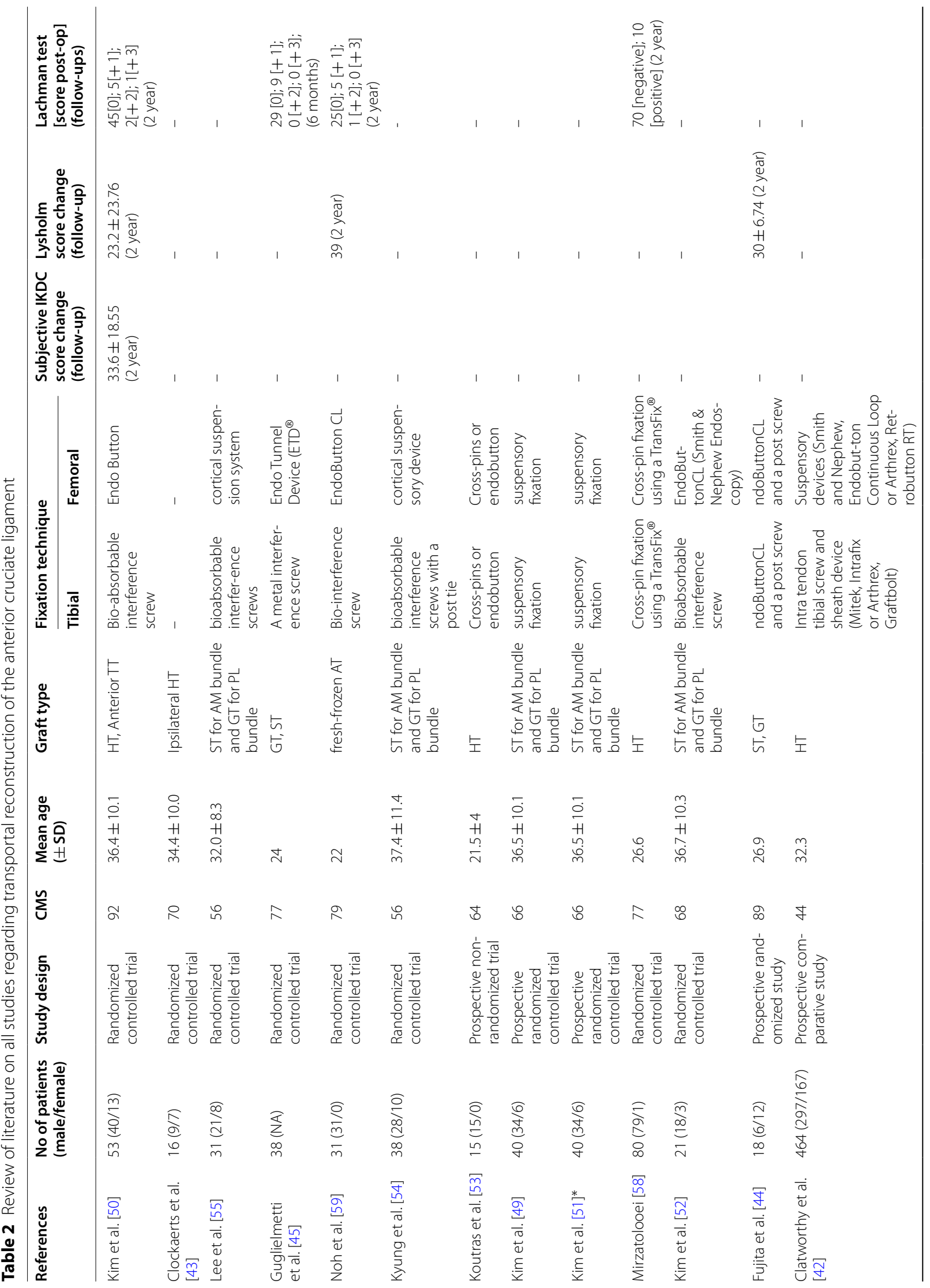




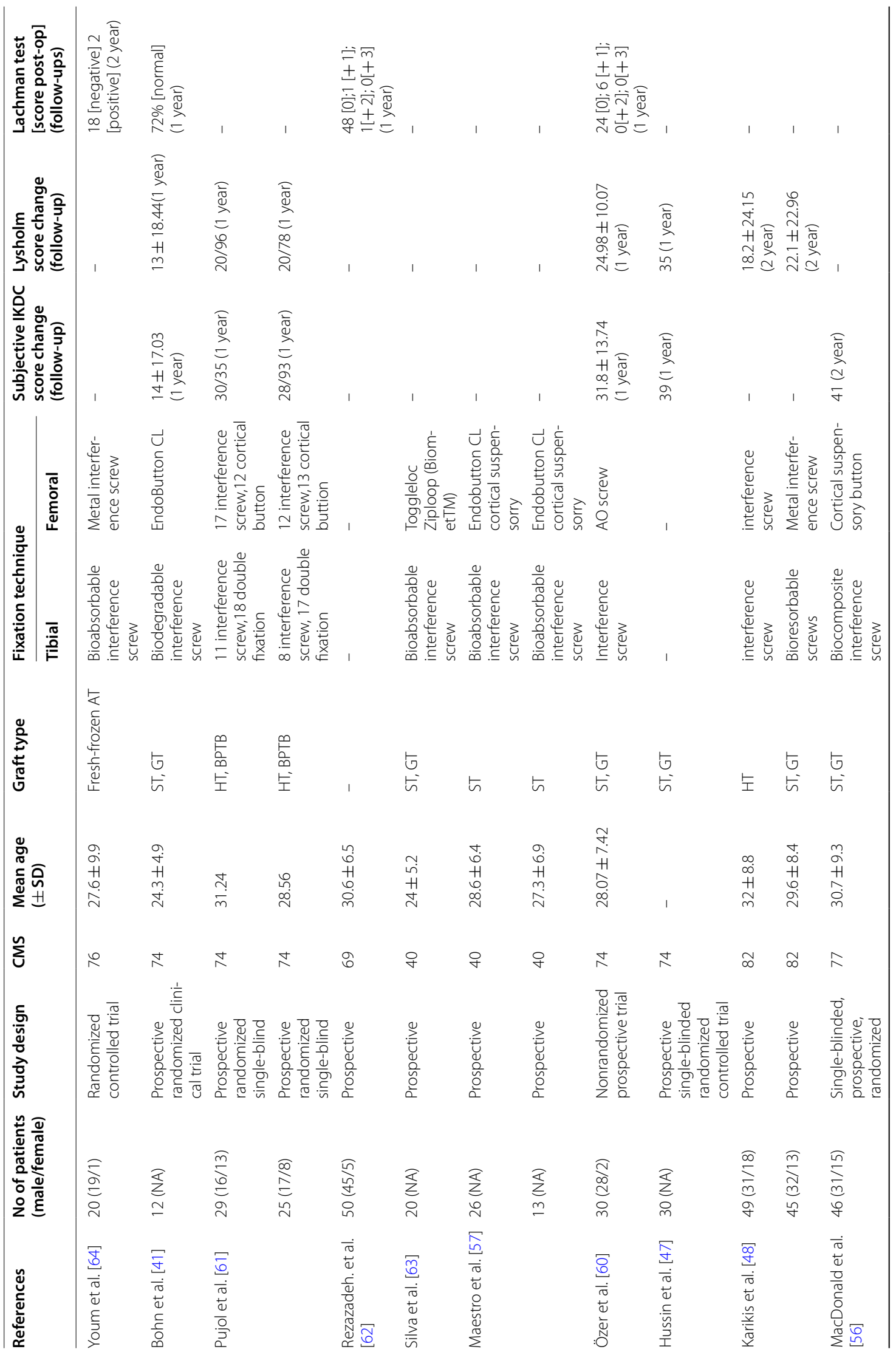




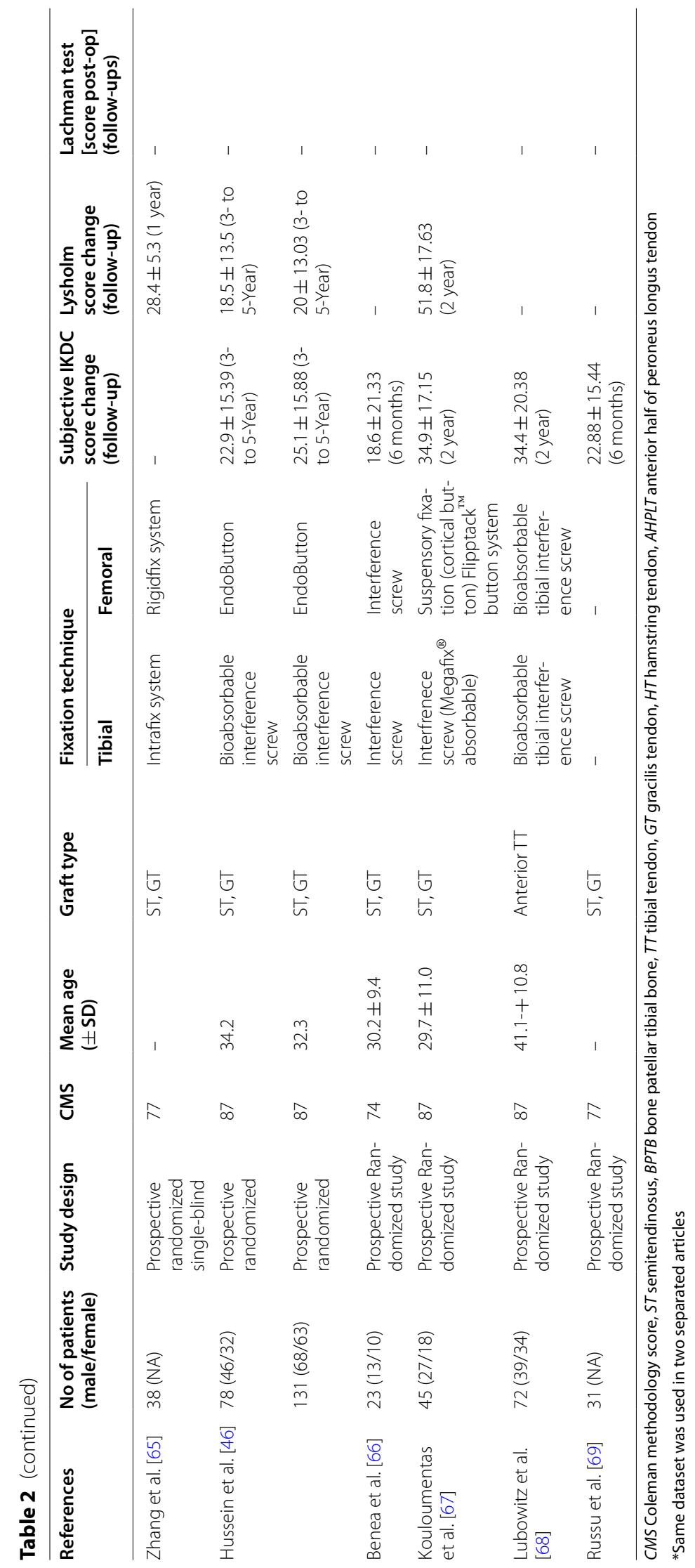


Table 3 Summary of data in literature regarding All inside technique (AIT) and transportal (TP) technique in anterior cruciate ligament reconstruction

\begin{tabular}{|c|c|c|}
\hline Variables & AIT $n=923$ & TP $n=1678$ \\
\hline \multicolumn{3}{|l|}{ Gender; n(\%) } \\
\hline Male & $557(62.58 \%)$ & $846(73.63 \%)$ \\
\hline Female & $333(37.42 \%)$ & $303(26.37 \%)$ \\
\hline Age (years); mean (SD) & $30.06(6.21)$ & $31.54(5.82)$ \\
\hline \multicolumn{3}{|l|}{ Population of study type of injury; n(\%) } \\
\hline Isolated & $131(48.52 \%)$ & $31(20.53 \%)$ \\
\hline Concomitant & $139(51.48 \%)$ & $95(62.91 \%)$ \\
\hline Complete ACL rupture & - & $25(16.56 \%)$ \\
\hline $\begin{array}{l}\text { Interval between time of injury till surgery (weeks); mean } \\
\text { (SD) }\end{array}$ & $23.96(14.07)$ & $76.65(32.1)$ \\
\hline Average follow-up post-surgery (weeks); mean (SD) & $31.11(1.78)$ & $26.7(5.18)$ \\
\hline Modifications in technique & $\begin{array}{l}\text { All epiphyseal AIT: } 15 \text { (6.98\%) } \\
\text { Double-bundle AIT: } 24 \text { (11.16\%) } \\
\text { Trans-lateral: } 148 \text { (68.84\%) } \\
\text { Transtibial: } 20 \text { (9.3\%) } \\
\text { Partial- transphyseal: } 8 \text { (3.72\%) }\end{array}$ & $\begin{array}{l}\text { Single bundle: } 302 \text { (49\%) } \\
\text { Double bundle: } 314 \text { (50.97\%) }\end{array}$ \\
\hline Graft type & $\begin{array}{l}\text { Semitendinosus: } 664 \text { (81.47\%) } \\
\text { Tibialis anterior tendon: } 134 \text { (16.44\%) }\end{array}$ & $\begin{array}{l}\text { Semitendinosus and gracilis: } 768 \text { (49.83\%) } \\
\text { Hamstring: } 670 \text { (43.48\%) } \\
\text { Achilles: } 51 \text { (3.3\%) }\end{array}$ \\
\hline \multicolumn{3}{|l|}{ Graft source; n(\%) } \\
\hline Autograft & $598(76.67 \%)$ & $1063(84.3 \%)$ \\
\hline Allograft & $182(23.33 \%)$ & $198(15.7 \%)$ \\
\hline \multicolumn{3}{|l|}{ Spinning; $n(\%)$} \\
\hline Double & $134(13.97 \%)$ & $103(29.5 \%)$ \\
\hline Quadruple & $712(74.24 \%)$ & $83(23.78 \%)$ \\
\hline Six-strand & - & $163(46.7 \%)$ \\
\hline 8-strand & $113(11.78 \%)$ & - \\
\hline \multicolumn{3}{|l|}{ Drilling technique; $\mathrm{n}(\%)$} \\
\hline Femoral & $\begin{array}{l}\text { Inside out: } 433 \text { (48\%) } \\
\text { Anteromedial: } 177(19.62) \\
\text { Outside-in: } 101 \text { (11.19\%) } \\
\text { Retro-drill: } 109 \text { (12.08\%) } \\
\text { Anterograde/retrograde: } 82 \text { (9.09\%) }\end{array}$ & $\begin{array}{l}\text { Offset guide: } 16(14.41 \%) \\
\text { Inside out complete tunnel: } 23(20.72 \%) \\
\text { Anteromedial portal technique: } 72(64.86 \%)\end{array}$ \\
\hline \multirow[t]{3}{*}{ Tibial } & Inside-out: 475 (52.66\%) & Tibial guide: 74 \\
\hline & Outside in: 79 (8.75\%) & Outside in: 23 \\
\hline & Retro drill: 348 (38.58\%) & Antegrade cannulated drilling: 72 \\
\hline \multicolumn{3}{|l|}{ Socket and fixation; (mm) } \\
\hline Range Femoral/Tibial & $20-25 / 20-35$ & 35.5-39.9/- \\
\hline Average Femoral/Tibial & $20.62 / 31.77$ & $38.74(0.27) /-$ \\
\hline \multicolumn{3}{|l|}{ Rehabilitation; mean (SD; range) } \\
\hline Return to sports (months) & $7(1.73 ; 4-12.5)$ & $8.3(3.23 ; 6-12)$ \\
\hline \multicolumn{3}{|l|}{ Complications; n(\%) } \\
\hline Total & $54(8.26 \%)$ & $55(6.62 \%)$ \\
\hline Graft failure & $14(25.93 \%)$ & $5(9.09 \%)$ \\
\hline ACL failure & $10(18.25 \%)$ & $36(65.45 \%)$ \\
\hline Paresthesia & $9(16.67 \%)$ & \\
\hline Re-operation & $9(16.67 \%)$ & \\
\hline Meniscus injury & $6(11.11)$ & \\
\hline Septic arthritis & $3(5.5 \%)$ & \\
\hline Superficial infection & $3(5.5 \%)$ & \\
\hline Deep infection & $3(5.5 \%)$ & \\
\hline
\end{tabular}


Table 3 (continued)

\begin{tabular}{lll}
\hline Variables & AIT $\boldsymbol{n}=\mathbf{9 2 3}$ & TP $\boldsymbol{n}=\mathbf{1 6 7 8}$ \\
\hline Hypoesthesia & $2(3.7 \%)$ & \\
Neurapraxia & $2(3.7 \%)$ & $1(1.82 \%)$ \\
Hemarthrosis & $2(3.7 \%)$ & $3(5.45 \%)$ \\
Cyclops syndrome & $2(3.7 \%)$ & \\
Wound dehiscence & $1(1.85 \%)$ & $2(3.64 \%)$ \\
Flexion loss & $1(1.85 \%)$ & $1(1.82 \%)$ \\
Arthrofibrosis & $1(1.85 \%)$ & \\
Superficial hematoma & $1(1.85 \%)$ & \\
\hline
\end{tabular}

ACL: Anterior Cruciate Ligament; SD: Standard Deviation

closer to the lateral wall of the notch and therefore disregards the need for notchplasty for visualization and operating [71].

The AM portal is one of the main strengths of the TP technique which allows the surgeon to obtain the optimal setting for ACLR by adjusting the port based on his understanding of the femoral structure and skills [72]. Among the other advantages of this technique is that the horizontally positioning of the graft results in a decrease in rotational instability [71]. Furthermore, the anatomical positioning of the femoral tunnel in the TP technique has resulted in improved stability based on biomechanical and clinical studies; however, the longterm clinical results and ACLR failure are still a matter of debate [18, 46, 73-75].

The difficulty of seating the endoscopic aimer and maintaining the aimer in a hyper-flexed knee is a frequent criticism of the TP technique. Another disadvantage of the TP technique is portal tightening and difficulty viewing in hyperflexion [10]. Moreover, technically challenging short or bicortical sockets, which can limit fixation options, possible damage to the articular cartilage, increased risk of injury to the common peroneal nerve, posterior-wall blowout, increased revision rate, and extension loss during the stance phase are among the other weaknesses of the TP technique that can affect the clinical outcome after ACLR [18, 53, $65,76,77]$. Furthermore, some studies have shown no definite advantages of the TP-ACLR and its modifications compared to the transtibial-ACLR regarding their clinical outcomes $[46,75,78,79]$.

All-inside technique is considered as a new minimally invasive option for ACLR. The all-inside technique differs from other ACLR approaches in that it uses a "socket" or "half-tunnel" on both the femoral and tibial sides [80, 81]. Reduced incidence of complications such as tibial plateau fractures; more anatomic placement of the tibial tunnel; improved bone-graft integration as a result of manual drilling; improved cosmesis; increased postoperative muscle, tendon, and bone preservation; and improvements in long-term function are among the AIT's proposed benefits [37, 66, 81, 82]. According to Lubowitz, a reduction in postoperative pain can be attributed to a reduction in tibial skin incisions and tibial periosteal irritation [21]. Furthermore, the use of the socket has been proposed to accelerate graft maturation and prevent tunnel enlargement due to dead space elimination [22].

All-inside ACLR technique has some advantages over conventional reconstruction technique that has led to wider use of this technique over the past years. The most noticeable advantage is the elimination of the large incision on the medial side of the tibia required for tibial drilling, which improves the cosmetic aspect [83, 84]. Moreover, creating sockets rather than full tunnels have some benefits including removing fewer bony structures which lead to less post-operative pain and inflammation, along with bone preservation in cases in which subsequent multiple ligament reconstruction is needed in the near future $[21,68,85]$. AIT-ACLR is a promising technique for reliably creating appropriately wide grafts without the requirement for allograft augmentation [86], which can be performed by harvesting a single semitendinosus graft, while also preserving the gracilis tendon. Since the hamstring tendon is considered as a secondary medial stabilizer of the knee and intact gracilis tendon can again be used if additional surgeries are needed; Additionally, gracilis sparing technique is beneficial to functional activity and sports with high demand on hamstring muscle strength [87]. Thus a technique that only harvest semitendinosus tendon seems to be superior to others $[88,89]$.

There is concern about the windshield wiper and bungee cord phenomenon that may occur with suspensory fixation. Prior studies evaluating sockets drilled with an all-inside ACL technique have revealed less socket expansion and preserved bone stock compared to full tunnels seen in standard ACL techniques on $\mathrm{x}$-ray and CT scans $[90,91]$. This is extremely crucial when drilling the tibial socket for all-inside ACL suspensory fixation because it reduces the risk of tibial microfracture trauma seen with 


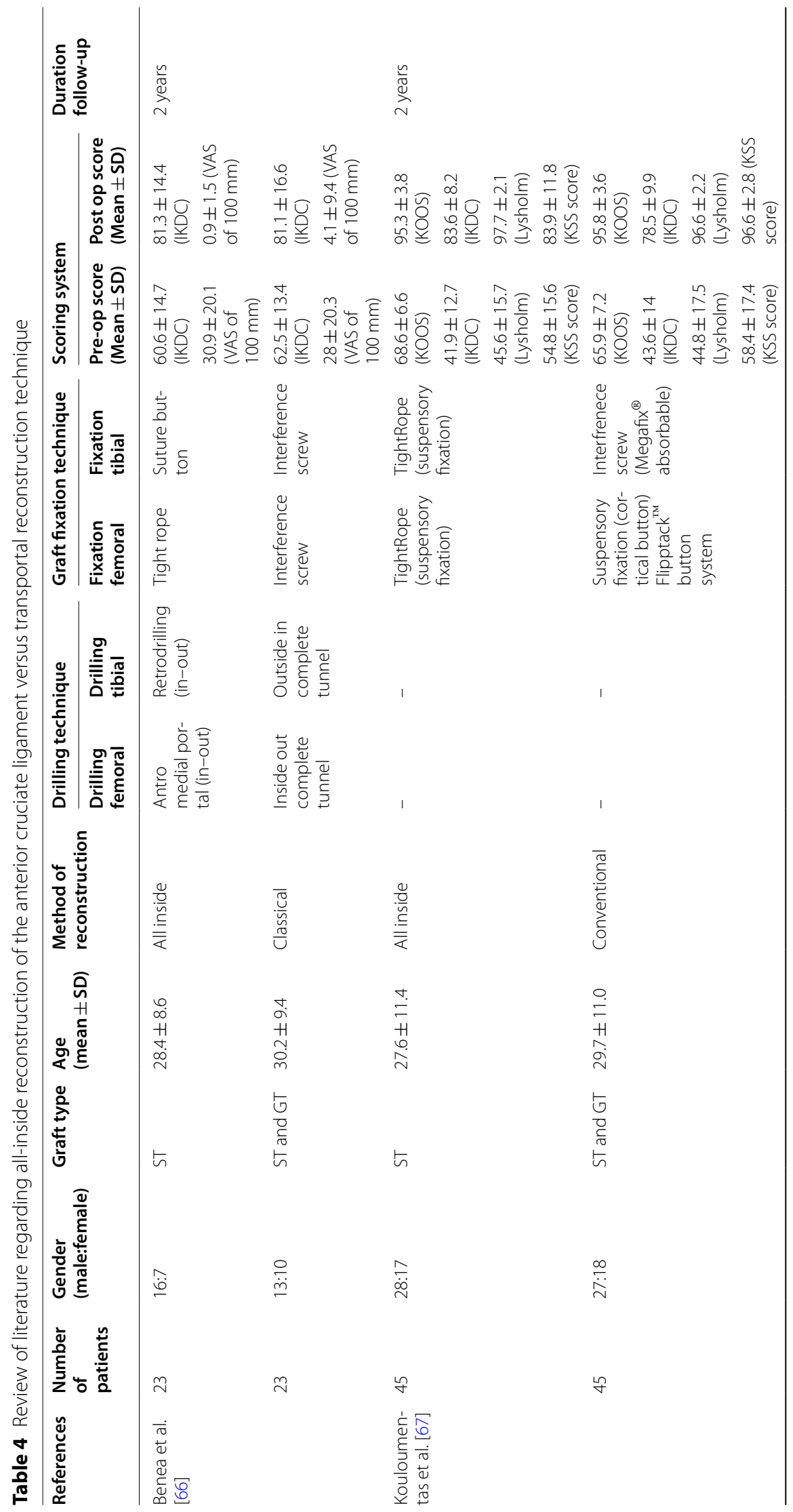




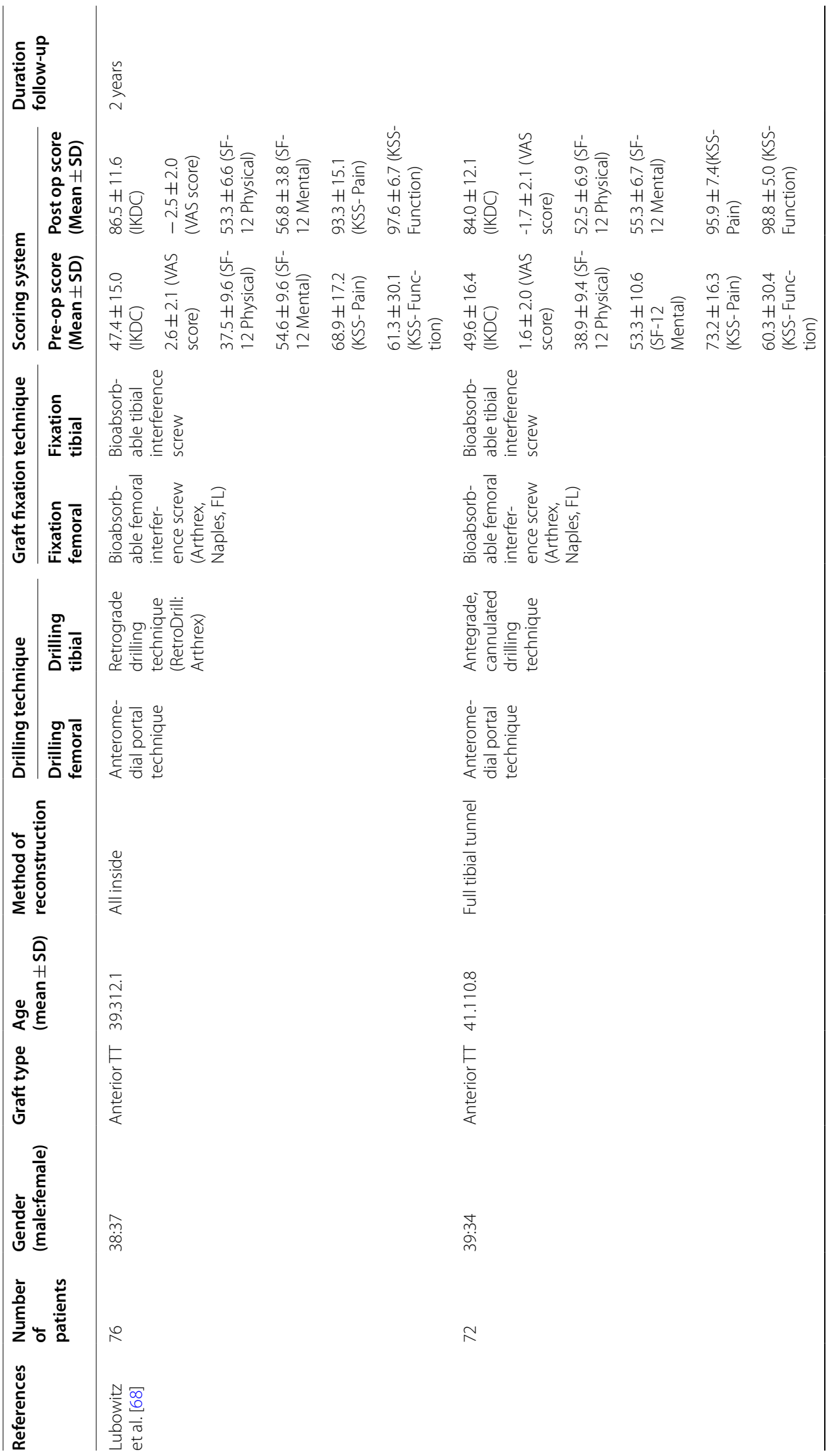




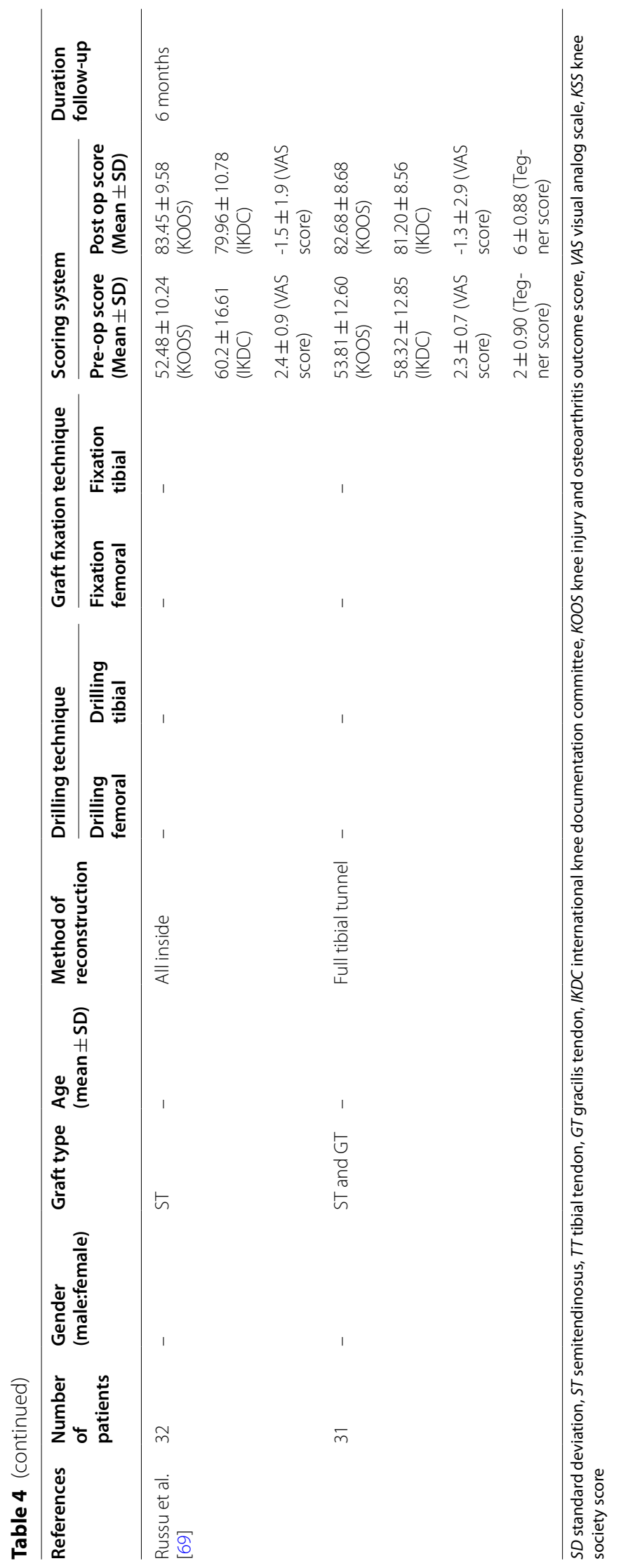


Table 5 Change of scores among All-inside and transportal anterior cruciate ligament reconstruction based on scoring method and follow-up duration

\begin{tabular}{|c|c|c|c|c|c|}
\hline \multirow[t]{2}{*}{ Scoring system } & \multirow[t]{2}{*}{ Technique } & \multicolumn{4}{|c|}{ Change of score during follow-up } \\
\hline & & 6 months & 1 year & 2 years & $3-5$ years \\
\hline \multirow[t]{2}{*}{ KOOS } & AlT & $+30.97(14.02)$ & +28.1 & $+29.97(22.71)$ & - \\
\hline & $\mathrm{TP}$ & $+28.87(15.3)$ & $+20.68(7.39)$ & $+29.9(8.05)$ & - \\
\hline \multirow[t]{2}{*}{ IKDC } & AlT & $+28.04(16.42)$ & $+40.58(13.13)$ & $+38.99(14.41)$ & - \\
\hline & $\mathrm{TP}$ & $+25.8(16.49)$ & $+34.47(6.01)$ & $+34.09(15.39)$ & $+24.28(15.7)$ \\
\hline \multirow[t]{2}{*}{ KT-1000 } & AlT & $-5.5(0.9)$ & $-4.34(1.947)$ & $-3.94(2.15)$ & - \\
\hline & $\mathrm{TP}$ & - & $-1.8(4.41)$ & $-2.87(3.5)$ & - \\
\hline \multirow[t]{2}{*}{ Lysholm } & AIT & & $+31.49(9.95)$ & $+37.13(10.48)$ & - \\
\hline & $\mathrm{TP}$ & $+28(10.83)$ & $+28.76(6.16)$ & $+27.99(18.46)$ & $+19.44(13.2)$ \\
\hline \multirow[t]{2}{*}{ VAS } & AIT & - & $-5.54(1.15)$ & $-3.56(2.14)$ & - \\
\hline & $\mathrm{TP}$ & $-12.25(14.72)$ & - & $-3.3(2.9)$ & - \\
\hline \multirow[t]{4}{*}{ Short form-12 scoring system } & AIT & Physical: + 13.6 (3.69) & Mental:+5.2 (9.22) & Physical:+ 16.7 (6.61) & - \\
\hline & & Mental: + 4.9 (9.33) & Physical + 16.47 (10.37) & Mental:+44.26 (9.84) & \\
\hline & TP & - & - & Physical: + 13.6 (11.66) & - \\
\hline & & & & Mental:+2.54 & \\
\hline
\end{tabular}

AIT all-inside technique, TP transportal technique, KOOS knee injury and osteoarthritis outcome score, IKDC International Knee Documentation Committee Subjective Knee Form, KT-1000 the KT-1000 knee arthrometer, VAS visual analog scale

full tunnel tibial drilling in standard ACL techniques [92]. Moreover, when closed-sockets are created, there is less graft length available for the windshield-wiper and bungee cord phenomenon compared to full tunnels [22].

Nevertheless, AIT-ACLR is also accompanied by some disadvantages. Adaptation and learning new surgery techniques is always time-consuming and requires practice as some techniques such as graft preparation, fixation, and socket creation involves going through applicable learning courses [22, 83]. Additionally, when creating a socket via retro drill, necessary precautions must be considered to avoid damaging the extra-articular surface [27]. In the aspect of graft fixation, it is reported that suspensory fixation might increase the risk of tunnel widening due to the "windshield wiper" phenomenon $[93,94]$. On the other hand, circumferential filling of the socket with the graft might decrease the synovial fluid backflow into the socket and increased bone to graft contact compared to interference screws [30, 95].

The optimal outcome scoring system for evaluating the outcome of ACLR is still a controversial issue, in which various subjective or objective scoring methods such as IKDC, Lysholm, KSS, SF-12, KOOS, and VAS scoring systems were used among the studies. The overall perspective was that there is no significant difference regarding pre-operation and post-operation scores in both AIT and TP ACLR techniques, except regarding the VAS pain score [66-69]. However, there was no difference in narcotic drug consumption in both groups, patients who underwent AIT-ACLR surgery reported lower VAS pain scores and a more rapid decrease in pain in the following months after surgery $[66,68]$. Furthermore, Kouloumentas et al. [67] reported a superior knee flexion strength in those who underwent all-inside surgery compared to the conventional group. It is worth mentioning that surgery time in all-inside surgery was longer than TP, which can be explained by the fact that AIT is a new method for surgery and more experience will lead to shorter surgery durations $[66,68]$. Regarding post-op complications, AIT demonstrated fewer complications compared to the TP technique in four prospective studies directly comparing the two techniques. As sample sizes and reported complications were few, further studies in this manner are needed to conclude a better decision.

Graft selection and surgical technique during ACL reconstruction have always been a source of contention because they have a direct impact on the outcome. Recent studies, including our systematic review, have shown that AIT is equally effective to TP technique in terms of outcome, with lower pain score and lower midterm complications, highlighting the advantages of AIT over TP technique in the future. Graft length and thickness, on the other hand, are equally important in achieving good results. Given that the AIT requires quadrupled semitendinosus tendon, it was demonstrated in our review to achieve adequate graft length and thickness. Prior studies has shown that grafts with diameters less than $8 \mathrm{~mm}$ have a high graft failure rate [96-99]. Furthermore, grafts of $9 \mathrm{~mm}$ in diameter have been shown to reduce graft failure rate by $55 \%$ when compared to 
graft thickness of $7 \mathrm{~mm}$, and grafts of $9 \mathrm{~mm}$ or more in diameter have results comparable to patellar tendon graft in ACL reconstruction patients [99, 100]. However, the patient's height has an effect on the semitendinosus graft length and diameter, and a diameter of 8-9 $\mathrm{mm}$ may be difficult to achieve with an isolated semitendinosus in some patients, particularly those who are short. Future studies are recommended to evaluate the impact of height on adequacy of isolated semitendinosus graft in patients undergoing ACL reconstruction using AIT.

\section{Limitations}

This study has few limitations that need to be highlighted. Firstly, the modest sample size and fewer number of the comparison studies with studies having relatively short follow-up periods, thus fail to provide long-term clinical evidence. Further comparison and randomized controlled studies with more patients are warranted to evaluate the clinical outcomes and complications of the reported methods. Our review was limited to articles in the English language and focused on prospective clinical trials in order to decrease the chance of bias. Also, articles published after the search period were not included in this review. Moreover, for this review, the commonly used PubMed, Medline, Google Scholar, and EMBASE databases were searched. As a result, the literature that could have aided this study by reviewing other databases such as Cochrane Library, Web of Science, Scopus, SportDiscus, and CINAHL may have been overlooked. Lastly, the analysis was not performed in a blinded fashion, and data in some studies were missing. The use of various outcome measuring methods and missing data leads to the inability to perform a metaanalysis to quantify the overall outcome of the AIT versus TP technique.

\section{Conclusion}

Since the future trend in orthopedic surgery is toward less invasive and patients' satisfaction with good outcomes, AIT is a good alternative method considering preserving bony tissue and gracilis tendon with less postoperative pain, along with more knee flexor strength and equal outcomes compared to conventional surgery. However, modifications can be applied to improve this technique which requires further comparison studies and evaluations of various grafts, fixations, drilling methods, and outcomes.

\section{Abbreviations}

ACL: Anterior cruciate ligament; ACLR: Anterior cruciate ligament reconstruction; AHPLT: Anterior half of peroneus longus tendon; AIT: All-inside techniques; AM: Anteromedial; BPTB: Bone patellar tibial bone; GT: Gracilis tendon; HT: Hamstring tendon; IKDC: International knee documentation committee; MCMS: Modified Coleman Methodology Score; KOOS: Knee injury and osteoarthritis outcome score; KSS: Knee society score; SD: Standard deviation; ST: Semitendinosus; TP: Transportal; TT:Tibial tendon; VAS: Visual analog scale.

\section{Supplementary Information}

The online version contains supplementary material available at https://doi. org/10.1186/s13018-021-02872-x.

Additional file 1. Search strategy across online databases.

Additional file 2. Worksheet for data extraction of reviewed literature regarding anterior cruciate ligament reconstruction techniques.

\section{Acknowledgements \\ None.}

Authors' contributions

RB: Investigation, Conceptualization, Supervision, Methodology, Validation, Review, Editing and Revising - Original Draft; SA: Conceptualization, Investigation, Methodology, Validation, Review and Editing; RS: Methodology, Formal analysis, Writing — Original Draft; KR: Data Curation, Methodology, Writing Original Draft; AE: Data Curation, Methodology, Writing-Original Draft. All authors read and approved the final manuscript.

\section{Funding}

No financial support was received for this study.

\section{Availability of data and materials}

All data generated or analyzed during this study are included in this article [and its supplementary information files].

\section{Declarations}

Ethical approval of the study

Not applicable.

\section{Consent for publication}

Not applicable.

\section{Competing interests}

The authors declare that they have no competing interests.

\section{Author details}

${ }^{1}$ Department of Orthopaedic Surgery, Massachusetts General Hospital, Harvard Medical School, Boston, USA. ${ }^{2}$ Thoracic and Vascular Surgery Research Center, Shiraz University of Medical Science, Shiraz, Iran. ${ }^{3}$ Student Research Committee, Shiraz University of Medical Sciences, Shiraz, Iran.

Received: 8 September 2021 Accepted: 5 December 2021 Published online: 23 December 2021

\section{References}

1. Gage BE, Mcllvain NM, Collins CL, Fields SK, Dawn Comstock R. Epidemiology of 6.6 million knee injuries presenting to United States emergency departments from 1999 through 2008. Acad Emerg Med. 2012;19(4):378-85.

2. Sutton KM, Bullock JM. Anterior cruciate ligament rupture: differences between males and females. JAAOS. 2013;21(1):41-50.

3. Gopinathan P. Fate of the untreated anterior cruciate ligament-injured knee. J Orthop. 2017;14(3):A1.

4. Scopp JM, Jasper LE, Belkoff SM, Moorman CT III. The effect of oblique femoral tunnel placement on rotational constraint of the knee reconstructed using patellar tendon autografts. Arthrosc J Arthrosc Relat Surg. 2004;20(3):294-9.

5. Johnson DL, Swenson TM, Irrgang JJ, Fu FH, Harner CD. Revision anterior cruciate ligament surgery: experience from Pittsburgh. Clin Orthop Relat Res. 1996:325:100-9. 
6. Kohn D, Busche T, Carls J. Drill hole position in endoscopic anterior cruciate ligament reconstruction Results of an advanced arthroscopy course. Knee Surg Sports Traumatol Arthrosc. 1998;6(1):S13-5.

7. Marchant BG, Noyes FR, Barber-Westin SD, Fleckenstein C. Prevalence of nonanatomical graft placement in a series of failed anterior cruciate ligament reconstructions. Am J Sports Med. 2010;38(10):1987-96.

8. Chalmers PN, Mall NA, Yanke AB, Bach BR Jr. Contemporary anterior cruciate ligament outcomes: does technique really matter? Oper Tech Sports Med. 2013:21(1):55-63.

9. Basdekis G, Abisafi C, Christel P. Influence of knee flexion angle on femoral tunnel characteristics when drilled through the anteromedial portal during anterior cruciate ligament reconstruction. Arthrosc J Arthrosc Relat Surg. 2008;24(4):459-64.

10. Lubowitz JH. Anteromedial portal technique for the anterior cruciate ligament femoral socket: pitfalls and solutions. Arthrosc J Arthrosc Relat Surg. 2009;25(1):95-101.

11. Iriuchishima T, Goto B. Systematic Review of Surgical Technique and Tunnel Target Points and Placement in Anatomical Single-Bundle ACL Reconstruction. J Knee Surg. 2021;34(14):1531-8. https://doi.org/10. 1055/s-0040-1710521.

12. Miller CD, Gerdeman AC, Hart JM, Bennett CG, Golish SR, Gaskin C, Miller MD. A comparison of 2 drilling techniques on the femoral tunnel for anterior cruciate ligament reconstruction. Arthrosc J Arthrosc Relat Surg. 2011;27(3):372-9.

13. Neven E, D'Hooghe P, Bellemans J. Double-bundle anterior cruciate ligament reconstruction: a cadaveric study on the posterolateral tunnel position and safety of the lateral structures. Arthrosc J Arthrosc Relat Surg. 2008;24(4):436-40

14. Otsubo H, Shino K, Nakamura N, Nakata K, Nakagawa S, Koyanagi M Arthroscopic evaluation of $\mathrm{ACL}$ grafts reconstructed with the anatomical two-bundle technique using hamstring tendon autograft. Knee Surg Sports Traumatol Arthrosc. 2007;15(6):720-8.

15. Kondo E, Yasuda K. Second-look arthroscopic evaluations of anatomic double-bundle anterior cruciate ligament reconstruction: relation with postoperative knee stability. Arthrosc J Arthrosc Relat Surg. 2007:23(11):1198-209.

16. Wang JH, Kim JG, Lee DK, Lim HC, Ahn JH. Comparison of femoral graft bending angle and tunnel length between transtibial technique and transportal technique in anterior cruciate ligament reconstruction. Knee Surg Sports Traumatol Arthrosc. 2012;20(8):1584-93.

17. Song E-K, Kim S-K, Lim H-A, Seon J-K. Comparisons of tunnel-graft angle and tunnel length and position between transtibial and transportal techniques in anterior cruciate ligament reconstruction. Int Orthop. 2014;38(11):2357-62

18. Robin BN, Jani SS, Marvil SC, Reid JB, Schillhammer CK, Lubowitz JH. Advantages and disadvantages of transtibial, anteromedial portal, and outside-in femoral tunnel drilling in single-bundle anterior cruciate ligament reconstruction: a systematic review. Arthrosc J Arthrosc Relat Surg. 2015;31(7):1412-7.

19. Sahu SK, Ganesh A. All-inside technique versus conventional transportal anterior cruciate ligament reconstruction: a retrospective study. Int J Orthop. 2020;6(1):39-44.

20. Lynch JL, Anderson K. Anterior cruciate ligament reconstruction: allInside reconstruction. Oper Tech Sports Med. 2013;21(1):40-6.

21. Lubowitz JH. No-tunnel anterior cruciate ligament reconstruction: the transtibial all-inside technique. Arthrosc J Arthrosc Relat Surg. 2006;22(8):900.e901-900.e911.

22. Lubowitz JH. All-inside ACL: retroconstruction controversies. Sports Med Arthrosc Rev. 2010;18(1):20-6.

23. Smith PA, Schwartzberg RS, Lubowitz JH. No tunnel 2-socket technique: all-inside anterior cruciate ligament double-bundle retroconstruction. Arthrosc J Arthrosc Relat Surg. 2008;24(10):1184-9.

24. Nakamura K, Nakamura T, Horie M, Katagiri H, Otabe K, Nakagawa Y, Amemiya M, Sekiya I, Muneta T, Koga H. Anatomic femoral tunnel placement is difficult by the transtibial technique: comparison of three different femoral tunnel drilling techniques in double-bundle anterior cruciate ligament reconstructions. Knee Surg Sports Traumatol Arthrosc Off J ESSKA. 2020:28(2):584-93.

25. Coleman BD, Khan KM, Maffulli N, Cook JL, Wark JD. Studies of surgical outcome after patellar tendinopathy: clinical significance of methodological deficiencies and guidelines for future studies. Victorian Institute of Sport Tendon Study Group. Scand J Med Sci Sports. 2000:10(1):2-11.

26. Bi M, Zhao C, Zhang S, Yao B, Hong Z, Bi Q. All-inside single-bundle reconstruction of the anterior cruciate ligament with the anterior half of the peroneus longus tendon compared to the semitendinosus tendon: a two-year follow-up study. J Knee Surg. 2018;31(10):1022-30.

27. Blackman AJ, Stuart MJ. All-inside anterior cruciate ligament reconstruction. J Knee Surg. 2014:27(5):347-52

28. Bressy G, Brun V, Ferrier A, Dujardin D, Oubaya N, Morel N, Fontanin $\mathrm{N}$, Ohl X. Lack of stability at more than 12 months of follow-up after anterior cruciate ligament reconstruction using all-inside quadruplestranded semitendinosus graft with adjustable cortical button fixation in both femoral and tibial sides. Orthop Traumatol Surg Res. 2016;102(7):867-72.

29. Dujardin D, Fontanin N, Geffrier A, Morel N, Mensa C, OhI X. Muscle recovery after $A C L$ reconstruction with 4-strand semitendinosus graft harvested through either a posterior or anterior incision: a preliminary study. Orthop Traumatol Surg Res. 2015;101(5):539-42.

30. Lubowitz JH, Schwartzberg R, Smith P. Cortical suspensory button versus aperture interference screw fixation for knee anterior cruciate ligament soft-tissue allograft: a prospective, randomized controlled trial. Arthrosc J Arthrosc Relat Surg. 2015;31(9):1733-9.

31. Monaco E, Fabbri M, Redler A, Gaj E, De Carli A, Argento G, Saithna A, Ferretti A. Anterior cruciate ligament reconstruction is associated with greater tibial tunnel widening when using a bioabsorbable screw compared to an all-inside technique with suspensory fixation. Knee Surg Sports Traumatol Arthrosc Off J ESSKA. 2019;27(8):2577-84.

32. Nawabi DH, Jones KJ, Lurie B, Potter HG, Green DW, Cordasco FA. Allinside, physeal-sparing anterior cruciate ligament reconstruction does not significantly compromise the physis in skeletally immature athletes: a postoperative physeal magnetic resonance imaging analysis. Am J Sports Med. 2014;42(12):2933-40.

33. Otsuka H, Ishibashi Y, Tsuda E, Sasaki K, Toh S. Comparison of three techniques of anterior cruciate ligament reconstruction with bonepatellar tendon-bone graft. Differences in anterior tibial translation and tunnel enlargement with each technique. Am J Sports Med. 2003:31(2):282-8.

34. Buda R, Ruffilli A, Cavallo M, Pagliazzi G, Baldassarri M, Ferranti-Calderon E, Natali S, Giannini S. Anatomic all-inside ACL reconstruction: surgical technique and results. J Orthop. 2013;5(3):135-8.

35. Schurz M, Tiefenboeck TM, Winnisch M, Syre S, Plachel F, Steiner G Hajdu S, Hofbauer M. Clinical and functional outcome of all-inside anterior cruciate ligament reconstruction at a minimum of 2 years' follow-up. Arthroscopy. 2016;32(2):332-7.

36. Shah R, Srinivasan S, Hamed Y, Menon DK. Clinico-radiological outcomes following anatomical anterior cruciate ligament reconstruction using the TransLateral, all-inside technique. J Clin Orthop Trauma. 2019;11:S326-31.

37. Volpi P, Bait C, Cervellin M, Denti M, Prospero E, Morenghi E, Quaglia A. No difference at two years between all inside transtibial technique and traditional transtibial technique in anterior cruciate ligament reconstruction. Muscles Ligaments Tendons J. 2014:4(1):95.

38. Watanabe S, Takahashi T, Hino K, Kutsuna T, Ohnishi Y, Ishimaru M, Miura $\mathrm{H}$. Short-term study of the outcome of a new instrument for all-inside double-bundle anterior cruciate ligament reconstruction. Arthroscopy. 2015;31(10):1893-902.

39. Yasen SK, Borton ZM, Eyre-Brook Al, Palmer HC, Cotterill ST, Risebury MJ, Wilson AJ. Clinical outcomes of anatomic, all-inside, anterior cruciate ligament (ACL) reconstruction. Knee. 2017;24(1):55-62.

40. Brandsson S, Faxen E, Eriksson BI, Sward L, Lundin O, Karlsson J. Reconstruction of the anterior cruciate ligament: comparison of outside-in and all-inside techniques. Br J Sports Med. 1999;33(1):42-5.

41. Bohn MB, Sørensen H, Petersen MK, Søballe K, Lind M. Rotational laxity after anatomical $\mathrm{ACL}$ reconstruction measured by 3-D motion analysis: a prospective randomized clinical trial comparing anatomic and nonanatomic $A C L$ reconstruction techniques. Knee Surg Sports Traumatol Arthrosc. 2015;23(12):3473-81.

42. Clatworthy M, Sauer S, Roberts T. Transportal central femoral tunnel placement has a significantly higher revision rate than transtibial AM 
femoral tunnel placement in hamstring $\mathrm{ACL}$ reconstruction. Knee Surg Sports Traumatol Arthrosc Off J ESSKA. 2019;27(1):124-9.

43. Clockaerts S, Van Haver A, Verhaegen J, Vuylsteke K, Leenders T, Lagae KC, Verdonk P. Transportal femoral drilling creates more horizontal ACL graft orientation compared to transtibial drilling: a 3D CT imaging study. Knee. 2016;23(3):412-9.

44. Fujita N, Kuroda R, Matsumoto T, Yamaguchi M, Yagi M, Matsumoto A, Kubo S, Matsushita T, Hoshino Y, Nishimoto K, et al. Comparison of the clinical outcome of double-bundle, anteromedial single-bundle, and posterolateral single-bundle anterior cruciate ligament reconstruction using hamstring tendon graft with minimum 2-year follow-up. Arthroscopy. 2011;27(7):906-13.

45. Guglielmetti LGB, Cury RPL, de Oliveira VM, de Camargo OPA, Severino NR, Fucs PMMB. Anterior cruciate ligament reconstruction: a new cortical suspension device for femoral fixation with transtibial and transportal techniques. J Orthop Surg Res. 2014;9:110

46. Hussein M, van Eck CF, Cretnik A, Dinevski D, Fu FH. Prospective randomized clinical evaluation of conventional single-bundle, anatomic single-bundle, and anatomic double-bundle anterior cruciate ligament reconstruction: 281 cases with 3- to 5-year follow-up. Am J Sports Med. 2012;40(3):512-20.

47. Hussin EA, Aldaheri A, Alharbi H, Farouk HA. Modified transtibial versus anteromedial portal techniques for anterior cruciate ligament reconstruction, a comparative study. Open Access J Sports Med. 2018;9:199-213.

48. Karikis I, Ahldén M, Casut A, Sernert N, Kartus J. Comparison of outcome after anatomic double-bundle and antero-medial portal non-anatomic single-bundle reconstruction in ACL-injured patients. Knee Surg Sports Traumatol Arthrosc. 2017;25(4):1307-15.

49. Kim JG, Chang MH, Lim HC, Bae JH, Ahn JH, Wang JH. Computed tomography analysis of the femoral tunnel position and aperture shape of transportal and outside-in ACL reconstruction: do different anatomic reconstruction techniques create similar femoral tunnels? Am J Sports Med. 2013;41(11):2512-20

50. Kim JG, Kang SH, Kim JH, Lim CO, Wang JH. Comparison of clinical results, second-look arthroscopic findings, and MRI findings between the transportal and outside-in techniques for double-bundle anatomic anterior cruciate ligament reconstruction: a prospective, randomized controlled trial with a minimum 2-year follow-up. Am J Sports Med. 2018:46(3):544-56.

51. Kim JG, Wang JH, Ahn JH, Kim HJ, Lim HC. Comparison of femoral tunnel length between transportal and retrograde reaming outside-in techniques in anterior cruciate ligament reconstruction. Knee Surg Sports Traumatol Arthrosc Off J ESSKA. 2013;21(4):830-8.

52. Kim JG, Wang JH, Lim HC, Ahn JH. Femoral graft bending angle and femoral tunnel geometry of transportal and outside-in techniques in anterior cruciate ligament reconstruction: an in vivo 3-dimensional computed tomography analysis. Arthroscopy. 2012;28(11):1682-94.

53. Koutras G, Papadopoulos P, Terzidis IP, Gigis I, Pappas E. Short-term functional and clinical outcomes after $A C L$ reconstruction with hamstrings autograft: transtibial versus anteromedial portal technique. Knee Surg Sports Traumatol Arthrosc. 2013;21(8):1904-9.

54. Kyung BS, Kim JG, Chang M, Jang K-M, Lee SS, Ahn JH, Wang JH. Anatomic double-bundle reconstruction techniques result in graft obliquities that closely mimic the native anterior cruciate ligament anatomy. Am J Sports Med. 2013;41(6):1302-9.

55. Lee BH, Bansal S, Park SH, Wang JH. Eccentric graft positioning within the femoral tunnel aperture in anatomic double-bundle anterior cruciate ligament reconstruction using the transportal and outside-in techniques. Am J Sports Med. 2015;43(5):1180-8.

56. MacDonald P, Kim C, McRae S, Leiter J, Khan R, Whelan D. No clinical differences between anteromedial portal and transtibial technique for femoral tunnel positioning in anterior cruciate ligament reconstruction: a prospective randomized, controlled trial. Knee Surg Sports Traumatol Arthrosc Off J ESSKA. 2018;26(5):1335-42.

57. Maestro A, Suárez-Suárez MA, Rodríguez-López L, Villa-Vigil A. Stability evaluation after isolated reconstruction of anteromedial or posterolateral bundle in symptomatic partial tears of anterior cruciate ligament. Eur J Orthop Surg Traumatol. 2013;23(4):471-80.
58. Mirzatolooei F. Comparison of short term clinical outcomes between transtibial and transportal TransFix(R) femoral fixation in hamstring ACL reconstruction. Acta Orthop Traumatol Turc. 2012;46(5):361-6.

59. Noh JH, Roh YH, Yang BG, Yi SR, Lee SY. Femoral tunnel position on conventional magnetic resonance imaging after anterior cruciate ligament reconstruction in young men: transtibial technique versus anteromedial portal technique. Arthroscopy. 2013;29(5):882-90.

60. Özer M, Özer H, Selek HY, Baltaci YG, Harput G, Taşkesen A, Cetinkaya M. Radiological and functional comparison of single-bundle anterior cruciate ligament reconstruction: transtibial versus anteromedial technique. Turk J Med Sci. 2018;48(3):455-61.

61. Pujol N, Colombet P, Potel JF, Cucurulo T, Graveleau N, Hulet C, Panisset JC, Servien E, Sonnery-Cottet B, Trojani C, et al. Anterior cruciate ligament reconstruction in partial tear: selective anteromedial bundle reconstruction conserving the posterolateral remnant versus single-bundle anatomic $\mathrm{ACL}$ reconstruction: preliminary 1-year results of a prospective randomized study. Orthop Traumatol Surg Res. 2012;98(8 Suppl):S171-177.

62. Rezazadeh S, Ettehadi H, Vosoughi AR. Outcome of arthroscopic single-bundle anterior cruciate ligament reconstruction: anteromedial portal technique versus transtibial drilling technique. Musculoskelet Surg. 2016;100(1):37-41.

63. Silva A, Sampaio R, Pinto E. ACL reconstruction: comparison between transtibial and anteromedial portal techniques. Knee Surg Sports Traumatol Arthrosc. 2012;20(5):896-903.

64. Youm Y-S, Cho S-D, Lee S-H, Youn C-H. Modified transtibial versus anteromedial portal technique in anatomic single-bundle anterior cruciate ligament reconstruction: comparison of femoral tunnel position and clinical results. Am J Sports Med. 2014;42(12):2941-7.

65. Zhang Q, Zhang S, Li R, Liu Y, Cao X. Comparison of two methods of femoral tunnel preparation in single-bundle anterior cruciate ligament reconstruction: a prospective randomized study. Acta Cir Bras. 2012;27(8):572-6.

66. Benea H, d'Astorg H, Klouche S, Bauer T, Tomoaia G, Hardy P. Pain evaluation after all-inside anterior cruciate ligament reconstruction and short term functional results of a prospective randomized study. Knee. 2014:21(1):102-6.

67. Kouloumentas P, Kavroudakis E, Charalampidis E, Kavroudakis D, Triantafyllopoulos GK. Superior knee flexor strength at 2 years with all-inside short-graft anterior cruciate ligament reconstruction vs a conventional hamstring technique. Knee Surg Sports Traumatol Arthrosc. 2019;27(11):3592-8.

68. Lubowitz JH, Schwartzberg R, Smith P. Randomized controlled trial comparing all-inside anterior cruciate ligament reconstruction technique with anterior cruciate ligament reconstruction with a full tibial tunnel. Arthrosc J Arthrosc Relat Surg. 2013;29(7):1195-200.

69. Russu OM, Ciorcila E, Feier AM, Fleaca R, Zuh SG, loanovici AC, Gergely I. Early outcomes in anterior cruciate ligament reconstruction: full tibial tunnel technique compared to all-inside technique. Rev Chim. 2018;69(12):3753-5.

70. Mahnik A, Mahnik S, Dimnjakovic D, Curic S, Smoljanovic T, Bojanic I. Current practice variations in the management of anterior cruciate ligament injuries in Croatia. World J Orthop. 2013;4(4):309.

71. Kumar C, Gupta AK, Singh SK, Jain R. Transportal anterior cruciate ligament reconstruction with quadrupled hamstring tendon graft: a prospective outcome study. Indian J Orthop. 2017:51(5):600-5.

72. Liu A, Sun M, Ma C, Chen Y, Xue X, Guo P, Shi Z, Yan S. Clinical outcomes of transtibial versus anteromedial drilling techniques to prepare the femoral tunnel during anterior cruciate ligament reconstruction. Knee Surg Sports Traumatol Arthrosc. 2017;25(9):2751-9.

73. Steiner ME, Battaglia TC, Heming JF, Rand JD, Festa A, Baria M. Independent drilling outperforms conventional transtibial drilling in anterior cruciate ligament reconstruction. Am J Sports Med. 2009;37(10):1912-9.

74. Bedi A, MusahI V, Steuber V, Kendoff D, Choi D, Allen AA, Pearle AD, Altchek DW. Transtibial versus anteromedial portal reaming in anterior cruciate ligament reconstruction: an anatomic and biomechanical evaluation of surgical technique. Arthrosc J Arthrosc Relat Surg. 2011;27(3):380-90 
75. Alentorn-Geli E, Samitier G, Álvarez P, Steinbacher G, Cugat R. Anteromedial portal versus transtibial drilling techniques in $A C L$ reconstruction: a blinded cross-sectional study at two- to five-year follow-up. Int Orthop. 2010;34(5):747-54.

76. Bedi A, Raphael B, Maderazo A, Pavlov H, Williams RJ III. Transtibial versus anteromedial portal drilling for anterior cruciate ligament reconstruction: a cadaveric study of femoral tunnel length and obliquity. Arthrosc J Arthrosc Relat Surg. 2010;26(3):342-50.

77. Steiner ME, Murray MM, Rodeo SA. Strategies to improve anterior cruciate ligament healing and graft placement. Am J Sports Med. 2008;36(1):176-89.

78. Franceschi F, Papalia R, Rizzello G, Del Buono A, Maffulli N, Denaro V. Anteromedial portal versus transtibial drilling techniques in anterior cruciate ligament reconstruction: any clinical relevance? A retrospective comparative study. Arthroscopy. 2013;29(8):1330-7.

79. Chhabra A, Diduch DR, Blessey PB, Miller MD. Recreating an acceptable angle of the tibial tunnel in the coronal plane in anterior cruciate ligament reconstruction using external landmarks. Arthroscopy. 2004;20(3):328-30.

80. Morgan G. All-inside ACL reconstruction. Tech Bull. 1995.

81. Cerulli G, Zamarra G, Vercillo F, Pelosi F. ACL reconstruction with "the original all-inside technique." Knee Surg Sports Traumatol Arthrosc. 2011;19(5):829-31.

82. Wilson AJ, Yasen SK, Nancoo T, Stannard R, Smith JO, Logan JS. Anatomic all-inside anterior cruciate ligament reconstruction using the translateral technique. Arthrosc Tech. 2013;2(2):e99-104.

83. Lubowitz JH, Amhad $\mathrm{CH}$, Anderson K. All-inside anterior cruciate ligament graft-link technique: second-generation, no-incision anterior cruciate ligament reconstruction. Arthrosc J Arthrosc Relat Surg. 2011;27(5):717-27.

84. Bradley JP, Tejwani SG. All-inside patellar tendon anterior cruciate ligament reconstruction. Sports Med Arthrosc Rev. 2009;17(4):252-8.

85. Smith PA. An alternative method for "all-inside" anterior cruciate ligament reconstruction. Arthroscopy. 2007;23(4):451.

86. Jones PE, Schuett DJ. All-inside anterior cruciate ligament reconstruction as a salvage for small or attenuated hamstring grafts. Arthrosc Tech. 2018;7(5):e453-7.

87. Yosmaoglu HB, Baltaci G, Ozer H, Atay A. Effects of additional gracilis tendon harvest on muscle torque, motor coordination, and knee laxity in ACL reconstruction. Knee Surg Sports Traumatol Arthrosc Off J ESSKA. 2011;19(8):1287-92.

88. Mochizuki T, Akita K, Muneta T, Sato T. Pes anserinus: layered supportive structure on the medial side of the knee. Clin Anat Off J Am Assoc Clin Anat Br Assoc Clin Anat. 2004;17(1):50-4.

89. Gobbi A. Single versus double hamstring tendon harvest for $\mathrm{ACL}$ reconstruction. Sports Med Arthrosc Rev. 2010;18(1):15-9.

90. Kim SG, Kurosawa H, Sakuraba K, Ikeda H, Takazawa S, Takazawa Y. Development and application of an inside-to-out drill bit for anterior cruciate ligament reconstruction. Arthroscopy. 2005;21 (8):1012.

91. Osti M, Krawinkel A, Hoffelner T, Benedetto KP. Quantification of tibial bone loss in antegrade versus retrograde tunnel placement for anterior cruciate ligament reconstruction. Int Orthop. 2015;39(8):1611-4.

92. McAdams TR, Biswal S, Stevens KJ, Beaulieu CF, Mandelbaum BR. Tibial aperture bone disruption after retrograde versus antegrade tibial tunnel drilling: a cadaveric study. Knee Surg Sports Traumatol Arthrosc Off J ESSKA. 2008;16(9):818-22.

93. Monaco E, Bachmaier S, Fabbri M, Lanzetti RM, Wijdicks CA, Ferretti A. Intraoperative workflow for all-inside anterior cruciate ligament reconstruction: an in vitro biomechanical evaluation of preconditioning and knot tying. Arthrosc J Arthrosc Relat Surg. 2018;34(2):538-45.

94. Monaco E, Fabbri M, Lanzetti RM, Del Duca A, Labianca L, Ferretti A. Biomechanical comparison of four coupled fixation systems for ACL reconstruction with bone socket or full-tunnel on the tibial side. Knee. 2017;24(4):705-10.

95. Smith PA, Stannard JP, Pfeiffer FM, Kuroki K, Bozynski CC, Cook JL. Suspensory versus interference screw fixation for arthroscopic anterior cruciate ligament reconstruction in a translational large-animal model. Arthrosc J Arthrosc Relat Surg. 2016;32(6):1086-97.

96. Magnussen RA, Lawrence JT, West RL, Toth AP, Taylor DC, Garrett WE. Graft size and patient age are predictors of early revision after anterior cruciate ligament reconstruction with hamstring autograft. Arthroscopy. 2012;28(4):526-31.
97. Park SY, Oh H, Park S, Lee JH, Lee SH, Yoon KH. Factors predicting hamstring tendon autograft diameters and resulting failure rates after anterior cruciate ligament reconstruction. Knee Surg Sports Traumatol Arthrosc Off J ESSKA. 2013;21(5):1111-8.

98. Conte EJ, Hyatt AE, Gatt CJ, Dhawan A. Hamstring autograft size can be predicted and is a potential risk factor for anterior cruciate ligament reconstruction failure. Arthroscopy. 2014;30(7):882-90.

99. Spragg L, Chen J, Mirzayan R, Love R, Maletis G. The effect of autologous hamstring graft diameter on the likelihood for revision of anterior cruciate ligament reconstruction. Am J Sports Med. 2016;44(6):1475-81.

100. Snaebjörnsson T, Hamrin-Senorski E, Svantesson E, Karlsson L, Engebretsen L, Karlsson J, Samuelsson K. Graft diameter and graft type as predictors of anterior cruciate ligament revision: a cohort study including 18,425 patients from the Swedish and Norwegian national knee ligament fregistries. J Bone Jt Surg Am. 2019;101(20):1812-20.

\section{Publisher's Note}

Springer Nature remains neutral with regard to jurisdictional claims in published maps and institutional affiliations.

Ready to submit your research? Choose BMC and benefit from:

- fast, convenient online submission

- thorough peer review by experienced researchers in your field

- rapid publication on acceptance

- support for research data, including large and complex data types

- gold Open Access which fosters wider collaboration and increased citations

- maximum visibility for your research: over 100M website views per year

At BMC, research is always in progress.

Learn more biomedcentral.com/submissions 